\title{
Short and long term side effect of colistin treatment in preterm infants
}

\author{
Sadık Yurttutan ${ }^{1 \oplus}$, Burcu Cantay Atalay ${ }^{2 \odot}$ \\ ${ }^{1}$ Division of Neonatology and ${ }^{2}$ Department of Pediatrics, Kahramanmaraş Sütçü Imam University Faculty of Medicine, \\ Kahramanmaraş, Turkey.
}

\section{Dear Editor,}

We read with interest the recently published article by Kaya Aksoy G et al. ${ }^{1}$ in which the side effects associated with colistin use in premature infants were evaluated.

In this study, 47 premature infants were evaluated in terms of their serum creatinine, AST, ALT and electrolytes before and during colistin use; the relationship between these parameters and colistin use was investigated. Among the side effects, the researchers emphasized that acute kidney injury (AKI) was the most prevalent, occurring in 17\% of cases. They also reported that AKI had a significant relationship to gestational age and aminoglycoside use. In the study, the notable electrolyte disorders that colistin use was associated with were hypomagnesemia, hypocalcemia and hypokalemia. This study found a link between hepatotoxicity and colistin use, which has not been mentioned as a side effect by similar studies conducted in the past. The study also reported that colistin less frequently caused AKI in premature newborns compared to pediatric patients, and that electrolyte disorders were more common in these newborns, indicating that they should be monitored for electrolyte imbalances, especially hypomagnesemia.

Recently, there has been an increase in the number of studies evaluating the effectiveness as well as the safety of colistin. These studies have

Sadık Yurttutan

dryurttutan@gmail.com

Received 17th November 2020, accepted 11th October 2021. primarily been conducted on term newborns or pediatric patients, rather than pre-terms. We would like to share the data of one of our largest studies conducted at the Kahramanmaraş Sütcü İmam University, Faculty of Medicine's Neonatal ICU, in which we evaluated the side effects and safety principles of colistin on 121 premature babies between 2014-2016. Similar to other studies conducted on infants. Our study reported nephrotoxicity to be the most common side effect (10.7\%). Çakır U and colleagues' publication mentioned side effects of bartter-like syndrome, to which we observed tubulopathy in 3 patients in our study. ${ }^{2}$ Similar to the results of Kaya Aksoy G and colleagues as well as Alan S and colleagues magnesium levels of the cases in our study decreased significantly after the use of colistin. ${ }^{1,3}$ Prolonged intolerance of the gastrointestinal system was a side effect unprecedented in other studies but was observed in $9.1 \%$ of cases in our study, which diminished alongside the discontinuation of colistin. 10 patients developed cholestasis, and although the clinical signs and symptoms subsided, total resolve occurred only after discontinuation.

A study on very low birth weight infants reported that the rate of nephrotoxicity increased as birth weight decreased; however, our study did not find a statistically significant correlation between kidney failure and birth weight. ${ }^{4}$

It should be noted that preterm newborns taking colistin should not only be monitored for short term problems, but also for long term problems. In our study, which was a follow-up of our first study, we monitored the long term ototoxic effects of colistin treatment on preterm 
infants; the hearing of 30 premature infants taking colistin was evaluated over a long period and 1 patient was discovered to have developed bilateral and 2 patients unilateral hearing loss. This is the first study reporting colistin associated hearing loss in premature infants. ${ }^{5}$

Preterm infants taking colistin treatment should be closely monitored for acute side effects (renal tubulopathy, hepatopathy, enteropathy) and should especially be followed up for ototoxicity in the long-term follow-up.

Key words: colistin, preterm, side effect.

\section{REFERENCES}

1. Kaya Aksoy G, Özyazıcı Özkan SE, Tezel G, Dayar GT, Köşker M, Doğan ÇS. Assesment of colistin related side effects in premature neonates. Turk J Pediatr 2020; 62: 795-801. https://doi.org/10.24953/ turkjped.2020.05.011
2. Cakir U, Alan S, Zeybek C, et al. Acquired Bartter like syndrome associated with colistin use in a preterm infant. Ren Fail 2013; 35: 411-413. https:// doi.org/10.3109/0886022X.2012.761084

3. Alan S, Yildiz D, Erdeve O, et al. Efficacy and safety of intravenous colistin in preterm infants with nosocomial sepsis caused by Acinetobacter baumannii. Am J Perinatol 2014; 31: 1079-1086. https://doi.org/10.1055/s-0034-1371361

4. Ilhan O, Bor M, Ozdemir SA, Akbay S, Ozer EA. Efficacy and safety of intravenous colistin in very low birth weight preterm infants. Paediatr Drugs 2018; 20: 475-481. https://doi.org/10.1007/s40272-0180301-5

5. Sarica S, Yurttutan S. An evaluation of hearing in infants administered with colistin in the premature neonatal intensive care unit. J Matern Fetal Neonatal Med 2018; 31: 2918-2922. https://doi.org/10.1080/147 67058.2018.1479388 